\title{
E-Learning Adoption inside Jordanian Organizations from Change Management Perspective.
}

\author{
doi:10.3991/ijet.v5i2.1260 \\ O.K. Harfoushi ${ }^{1}$, R.F. Obiedat ${ }^{1}$ and S.S. Khasawneh ${ }^{2}$ \\ ${ }^{1}$ University of Jordan, Amman, Jordan \\ ${ }^{2}$ University of Manchester, Manchester, United Kingdom
}

\begin{abstract}
The objective of this research is to build a complete e-Learning adoption model which can be used to increase the acceptance of e-learning inside Jordanian organizations. This objective is achieved through the analysis of the e-learning adoption process in two different Jordanian case studies.
\end{abstract}

Index Terms—Change Management, e-Learning, Jordan

\section{INTRODUCTION}

Many studies were conducted in order to investigate different aspects of E-Learning such as e-Learning styles, (Watkins, 2005; Coffield et. al., 2004), importance (Kruse, 2004; Nininger, 2001), satisfaction (Wang, 2003; Chen et al., 2004), evaluation (Newman, 2003; Massy, 2002; Coultas et al., 2004) and culture (Kamentz1 and Mandl2, 2002; Guzmán and Motz, 2005; Blanchard et al., 2005). However, few studies focus on the change management role for successful adoption of the e-Learning systems especially inside organizations. Electronic learning is considered to be a major educational innovation (Elgort, 2005); it becomes more and more important in today's knowledge-based economy (Wentling, T. et al, 2000) especially that learning and knowledge management are converging these days and they will be undividable in the near future (Cross and Dublin, 2002). Thus, companies and universities are increasingly implementing it, which reveal the raise need for such strategy, especially that they are spending a large amount of money buying and installing these systems.

Unfortunately, many of organizations failed to achieve the expected results and gain the systems maximum potential for many reasons (Windmill, 2005; Mackenzie, 2004; Elgort, 2005; Zemaky et al., 2004) which will be analyzed through this research. As Psycharis (2005) stated "As more and more companies and organizations turn towards the implementation of e-learning for the training of their human resources and many of these attempts fail, a particular model is needed so that the various organizations which are willing to implement e-learning or have implemented such policies and want to improve them". There is a common perception that the main reason behind the failure is the ignorance of change management issues as an essential part in the process beside the lack of alignment between the learning and the business needs (Mackenzie, 2004).
Furthermore, most organizations focus on technological issues which has to be their least concerns and neglect the more essential side concerning people, as it's easy to find a highly effective system and install it inside the organization, but in many cases these systems did not add any value for their organization because very few number of employees decided or motivated to use it. Hence the more essential element is to make a person accept this system and use it, which is the role of the change management (Windmill, 2005; Piskurich, 2003). As (Cowley et al., 2002) stated "elearning adoption is more about change than technology. Big-budget staff development of technical resources is a secondary stage in adoption - social issues and change management are first. Most organizations don't realize that..."

The researchers believe that human side presents the most important factor affecting e-Learning adoption success or failure. From this point, this study will focus on the change management role in e-Learning adoption and will analyze the reasons behind the low usage of online learning systems by investigating the main factors affecting the adoption process. Moreover, this study will try to provide the proper solutions through an appropriate change management model to guarantee the maximum usage and achieve the highest possible potential from deploying an electronic learning system especially inside Jordanian organizations.

\section{E-LEARNING CHANGE MANAGEMENT FACTORS}

Introducing new E-Learning system presents a significant change for the organization and like any other change inside the organization it needs careful planning and management (Mackenzie, 2004; Cross and Dublin, 2002; Rosenberg, 2006; Piskurich, 2003). Since it's impossible to change the way an organization and its people work only by implementing the change, it needs a careful analysis, planning, evaluation, communication, and of course management (Mackenzie, 2004). Change management forms a critical element in the success of e-Learning adoption. As aforementioned to handle the human side of change is more important and more difficult than the technological issues (Windmil, 2005).

Hiatt and Creasey (2003) Define change management as "the process and tools for managing the people side of change", while (Mackenzie, 2004) includes in her definition managing both people and business dimension simultaneously. On the other hand Goff (2000) and Singh and Waddell (2004) define change management in the organi- 
zation context as an organized approach to integrate technological change, which include both a formal process to evaluate the impact of change, and techniques to make users accept the change caused by introducing new technology and change their behavior to take full potential of this new IT functionalities, while (Rosenberg, 2006) focuses in his definition on developing the readiness and motivation of the employees in order to accept and utilize the new innovation. The researchers believe that all the definitions are right, each one describes certain side of change management and the change management definition maybe is combination of all.

Furthermore, there are always two perspectives to change; the individual perspective and the organizational perspective. The organizational perspective focuses on some issues such as the required investment, the return on investment (ROI), the impact on performance and customers, while the individualized perspective focuses on the benefits for the individual in term of performance, rewards and promotion, so change management needs to understand both perspectives to deal with each one from its own point of view (Hiatt and Creasey, 2003).

According to different scholars, it was found that the most important change management factors which play a key role in the success of e-Learning adoption are Leadership, Motivation, Culture and Human capabilities. The following paragraphs discuss what these factors are and why these factors are important to be studied.

\section{A. Leadership}

Leaders' main characteristic is the ability to communicate; leaders communicate their feeling about change, the degree they are confident their employee will succeed the change, their commitment to change, their connection and closeness to employee, their acceptance to employee reaction concerning the change and their willingness to receive employees' input and feedback regarding the change. When leaders communicate the right message, it helps decreasing resistance and, therefore, goes through the change smoothly and successfully (Bacal, 2008).

Leadership term has different meaning for different people; most definitions include the words team, influence and objectives. (de Jong \& Den Hartog, 2007) define leadership as "the process of influencing others towards achieving some kind of desired outcome". It's important to determine and support the leadership power for a successful e-Learning implementation (Cross and Dublin, 2002). Leaders are required to prepare the needed plan, form the appropriate change team, explain the reality to the team, clarify the nature of the change and the reason behind it, design the needed roadmap to achieve their goal and encourage their employees to participate and support that change (Hamilton, 2004; Kotter, 1996). (Cross and Dublin, 2002) stated "Leadership defines what the future should look like, aligns people with that vision, and inspires them to make it happen despite the obstacles". Since the leaders major role is to align the e-learning strategy and goals to fulfil the core business objectives and to ensure a continuous integration with business processes which guarantee permanent sustainability (Mackenzie, 2004).

In view of the fact that leaders are the most important change agent inside the organization, the first step to begin with is to guarantee their commitment and full support.
Because when the leaders show their willingness and commitment to learn and use the new system their employees will imitate them and follow their steps which increase their participation in e-Learning. The best way to do that is by marketing e-Learning benefits, objectives and other important issues to them and then let them experiment the e-Learning system themselves and make sure to give them the best accessible courses (Sullivan, 2002) because they have to be convinced themselves of change in order to be able to persuade their employees for the need of that change. (Bacal, 2008) suggests, against some people beliefs that, even if leaders still not committed to change or not confident of their ability to succeed, it is important to hide their feelings and keep showing commitment despite their own doubts, as if they show their negative feelings it is more probable to receive the same negative reaction from their staff.

Without effective leadership, there is no way to achieve the learner acceptance and succeed in change, since the employees are usually more affected by their direct supervisors than any other person. Leaders need to have the vision, transfer it to employees, understand the change and have strong commitment to it, lead by example, have the charisma and strong training and communications skills, and, most important, they need to make sure that the change process is aligned with the organization strategy (Cross and Dublin, 2002).

\section{B. Motivation}

Motivation is one of the most critical factors for eLearning adoption. In many cases, employees refuse to use the e-Learning systems for different reasons, so it is very important for change management to convince them to accept the change and motivate them to use the new system through any possible methods.

Many practices can be used by the organization in order to encourage people to use the new system, however, the strongest motivation is coming from inside. Employees have to be self-motivated since nobody can force any employee to learn, therefore, one of the most effective ways to motivate them is by explaining the value proposition and benefits they can gain by using the system.

\section{Culture}

Culture presents the main obstacle faced by organizations trying to adopt the e-Learning system (Wong, 2005). One of the most critical points regarding cultural issues is people resistance for change. Resistance presents a natural reaction for any new thing; in e-Learning case people first experience with learning contains classroom, books, desks with instructor in front of the class since the Greek, (Sullivan, 2002), this is the way of teaching people were used to and comfortable with. Transforming people from traditional learning methods into e-Learning presents a big cultural shift which needs a lot of work and time to change people perspective and accept the new learning style. So it's important to provide them with the needed time for the transition process because it's taking a large time for people to accept the new innovations or large changes (Sullivan, 2002). As (Peters, 2001, Rosenberg, 2006) stated "We need to talk about "e-forgetting," because to be successful at e-Learning, you have to forget the ways of your past." 


\section{Human Capabilities}

One of the main reasons lying behind people resistance to the new system is their fear from new technology because they do not know how to use it or do not have the needed skills and experiences to use it, especially the older one who did not grow with technology (Rosenberg, 2006). So people educational backgrounds, technological competences, self-efficacy, previous experience and skills in using computer and internet play a key role in people acceptance and adoption success (Cross and Dublin, 2002).

\section{RESEARCH PROCEDURES AND ANALYSIS}

The objective of this research is to build a complete eLearning adoption model which can be used to increase the acceptance of e-learning inside Jordanian organizations. This objective is achieved through the analysis of two different Jordanian case studies. The researchers interviewed many experts in those organizations and based on the results of these interviews, an adoption model is developed. Case study methodological pluralism is chosen to collect the needed data in order to investigate the main change management factors affecting the e-Learning adoption inside organizations.

The selection process for these cases started with contacting the biggest and most popular organizations in Jordan via emails, phone calls or simply by asking friends and relatives working in different organizations to find out the companies which already have an e-Learning system. In addition, some IT companies, especially those developing e-Learning solutions, were contacted in order to get a list of companies that have an e-Learning system. These companies were the most helpful and provided the main contacts, since they already sold their systems for some companies, they are expert in this field and they have the needed information because they already analyzed the Jordanian market.

A short list was prepared since the topic is still in the first stages in Jordan and there are not many organizations decided to implement such system yet for many reasons. After that, there was a preliminary visits and quick interviews for each company to understand its situation, the type of system they have, the stage they reach in the adoption process and how successful they were, in order to narrow the list and find out the most suitable cases for this study to facilitate performing in-depth analysis for each selected case.

As a result, two well-known Jordanian organizations which use e-Learning systems were chosen as the research case studies to make an in-depth analysis for each case in order to find precise answers for the research questions and help in achieving the research objective.

The first studied case is Talal Abu Ghazaleh organization which is an accounting; auditing, taxation and financial services organization in the Arab world. It is in the early stage of the e-Learning adoption process. It was important to study the plans they prepared for the adoption process, the steps they took in order to be ready for this new technological innovation, how was their first reaction for this experience and what are they arranging for the next steps.

Talal Abu Ghazaleh, founded in 1972, contains 71 offices spread over 29 different countries with more than 2000 professional employees, headquartered in AmmanJordan. There vision "we try harder to stay first". It offers a wide range of services such as Auditing and Taxation, Intellectual Property, Management Consulting, Financial services, Technology Transfer, Project Management and many other services. It includes different companies such as Talal Abu-Ghazaleh \& Co. International (TAGI), Talal Abu-Ghazaleh \& Co. Consulting (TAGCONSULTANTS), Talal Abu-Ghazaleh E-Training (TAG-CAMBRIDGEIT), Abu-Ghazaleh Intellectual Property and other companies.

The second case is Orange (Jordan Telecom Group, JTG). It plays a major role in the information and communications technology area in Jordan. It provides services such as Internet, mobile, fixed line services, high speed internet, prepaid cards and others. It presents the most successful story in adopting e-Learning system in Jordan, which helps in investigating the main acceptance factors for e-Learning system and the key elements behind their success, how each factor helps the adoption process and finds the role of change management in the success.

Based on the relevant literature review, a preliminary model was developed as shown in Figure 1. The model consists of four expected major change management factors; leadership, motivation, culture and human capabilities. It is believed that the four major change management factors affect the adoption of e-learning inside organization. Moreover, it is suggested that e-learning adoption can be measured through different elements such as productivity, system usage, performance, ROI...etc.

The main aim of the case studies was to determine if the expected factors are the actual factors affecting the eLearning adoption and if there are any other hidden factors concerning the adoption process in these organizations, this leads to develop a complete change management strategy that guarantee successful e-Learning adoption inside organizations.

The data was collected over four months of interviews, field observation and some documents analysis (Sep. 2008 - Dec. 2008). Almost four to five semi-structured face to face interviews were conducted in each company with eLearning managers, employees involved in the adoption process and some experts as well as users in the discussed field. It does not matter whether the interviewees are employed in the IT department or training departments. This variety helps in taking different perspectives about the same subject from people in different hierarchical layers with different backgrounds in each company. This increases the reliability of the interviews and collected information. The managers were the contacting points and the main informant for the other interviewees; they were interviewed more than once.

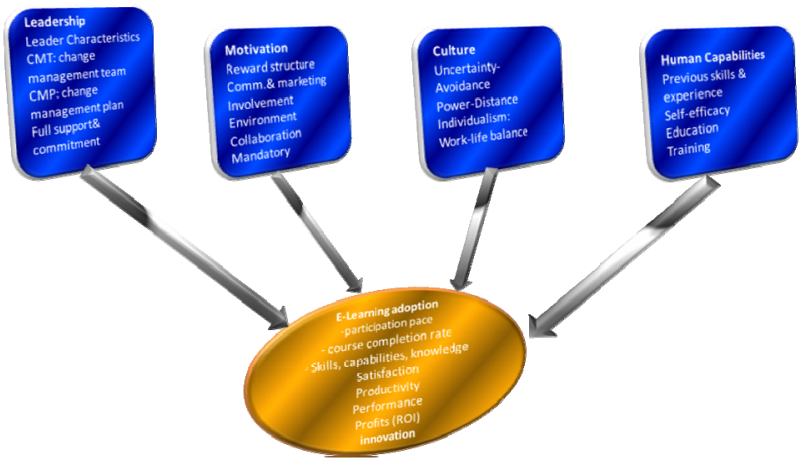

Figure 1. The preliminary Model 
All of the interviews were conducted in the companies' site. The interviews lasted around 1.5 hours, started with a brief introduction about the research objective and the aim of these interviews. The interview questions start with open-end questions to make sure to get all what the interviewee knows without the interviewer influence then move to more specific one concerning the expected factors from the previously mentioned theoretical model. This guarantees that the interviewees do not overlook any information.

Construct validity was taken into consideration during data collection stage; internal validity was maximized by using multiple sources of evidence such as interviews, documents analysis, observations... etc. Moreover, key interviewees reviewed the draft of their cases' report and their feedbacks were taken into consideration. External validity was guaranteed by using multiple cases "replication logic", each case gives the same expected results as other cases then replication takes place (Yin, 1994). Also the more variety in people, places and procedures within a case study and keep giving the same results the more external validity assured. Moreover, the examination between the cases and literature review authenticate external validity. Using multiple sources of evidence and replication logic enhanced the reliability as well.

Finally, cross case conclusions were drawn and the model was finalized. The cases not only provide information about the e-Learning system and the main factors affecting the adoption process inside these organizations, but also help in outlining a complete change management strategy that helps other companies to successfully adopt the e-Learning system from the first time or even the companies who have already failed to achieve the expected results from the first time to overcome the obstacles they faced.

\section{First Case Study: Talal Abu GHazaleh INTERNATIONAL}

Talal Abu Ghazaleh international has two separate departments responsible of the e-Learning system adoption inside the organization; the e-Learning department and training department. The e-Learning department is a part of the IT department. It is responsible of the development and implementation of the e-Learning system inside the organization, but the system in use now is not developed by the organization, it is developed by external company and implemented in the organization, since they are still in the development phase and did not finish their own system yet. The training department is responsible for the planning phase; identifying the training path, selecting the needed courses, monitoring the learning process, receiving feedbacks, motivating employees, measuring success and any other procedures helping the adoption process. The company has a central internal training department and each large company sector has another training manager with two training coordinators. These sections are independent but collaborate with each other.

Five people were interviewed inside the organization; two in the e-Learning department (one an e-Learning developer and the other an e-Learning specialist) and three in the training department; Executive director of the internal training and continuous education and two users of the system. Almost the same questions were asked to all interviewees.
The interviews started in the central internal training department with the company executive director of the internal training and continuous education; she was the key informant since she is the one responsible for anything concerning the e-Learning subject inside the organization. She explained the purpose behind being the first adaptor in implementing the e-Learning system. They were aiming to serve the organization main goals since it helps in saving time, effort and money as they have 80 offices around the world and need one training solution to all parts and the training issues were time and money consuming especially when they need to go outside the company to get the training. This is supported by what Piskurich (2003), Henderson (2003) and Cross and Dublin (2002) mentioned about the importance of e-Learning for the organizations. She added this technological innovation helps in meeting their goals and can give them ompetitive advantage against their rivals. Indeed, Rosenberg (2000) supports this as "The only thing that gives competitive advantage to an organization is what it knows, how it uses that knowledge and how fast it can learn something new".

Abu Ghazaleh has not a predefined for the change process; the people involved in the adoption process handle the change step by step. The process starts by studying their readiness for this new technological innovation; they make sure they have the needed infrastructure and equipments since each employee has his/her own PC with high speed internet connections, this is reinforced with what (Sullivan 2002; Sitze 2003; Van Dam 2004) stated that the proper environment presents one of the important factors affecting the adoption success. They take $0.5 \%$ from each company branch revenues for training expenses so they have no financial problems. They realized that e-Learning Return on Investment (ROI) is much more than its cost.

On the other hand, the company makes sure to have the needed competences as they make a pre-assessment exam prepared by Cambridge University for their staff to decide their training needs including language and computer skills if they pass it then they do not have to take the course, else they need to take it. They give training courses for them depending on their results; any one with good background in IT does not need more than 19 hours to finish the skills course, while the one who does not have any background needs 90 hours to finish all related topics, or they may request them to gain ICDL (international computer driving licence) certificate instead to ensure they have the sufficient computer skills needed to use the new system, moreover, to provide them with user manuals needed to be able to use the new system smoothly. This agrees with Sitze (2003) suggestion to make a usability testing to figure out the employees qualifications before deciding the needed training, and supported by Cross and Dublin (2002) study's result which states that people technological competences, previous experience and skills in using computer and internet play a key role in people acceptance and adoption success because when people become able to use the system they will be more willing to use it. They start with blended learning using instructors along with e-Learning to help the learning process in order to decrease the cultural resistance, encourage people to use the e-Learning system and convert the way of learning smoothly and slowly then try to go for complete e-Learning.

As for the leadership factor, the interviewees assure that leaders play a key role in e-Learning adoption success, so 
the organization must make sure that leaders should have certain characteristics. First of all they need to believe in change and the need for the new system as leaders' commitment is very important to the adoption success since a leader presents the mentor for his employees. Unfortunately, most of them do not have this kind of commitment. Sullivan (2002) suggests achieving that by marketing the e-Learning benefits, objectives and other important issues to them and then let them experiment the e-Learning system themselves. In addition, they ensure that leaders are specialist in training and field of work to know exactly what they are facing. Also, they need to have good communication skills in order to convince other employees to accept the change. Bacal (2008) argues that leaders communicate their feeling about change, the degree they are confident their employee will succeed the change and their commitment to change. When leaders communicate the right message it helps decrease resistance and go through the change smoothly and successfully. Leaders must have experience in this field, knowledge and background in training and available material; also their previous evaluations play a role in the selection process.

The training department followed many techniques in order to motivate people use the system. They believe that motivation presents one of the most important factors affecting the e-Learning adoption process. Ms. Hams Mdanat explains "employees have to be self-motivated if we want the system to succeed" which concur with what Piskurich (2003) mentioned. The strongest motivation to use the e-Learning system coming from inside, therefore, in order to meet that, they show them the benefits they can gain by using the system, they offer up-to-date information prepared by experts that are available only on their site and cannot be gained from any other sources which motivate people to access it. Also, they are given important certificates when succeed the exams at the end of the course. Whereas the interviewed users say they are selfmotivated as they can gain new knowledge and new skills for their job and it is paid by the company especially if it is a popular and an expensive course that they cannot afford alone, also they can gain certificates and it is time effective because they can do it at their desk. Besides, it is important for their yearly evaluation and consequently their promotions.

Training department uses many marketing techniques by emails and reminders explain what courses are available, why they need them, the period for the courses and where to find them. In addition they use group work via chat, forums, and emails and have tutor for each group to answer questions and give evaluations, but it is not applied largely; it depends on the material type, the availability of tutors and a need a team leader for each group, even though their employees prefer the group work to share opinions.

The department has a training needs' form to be distributed among employees on regular basis. This is a table contained the mandatory training, the optional training and any suggestions to be added and prioritize by employees. Then the department chooses the most frequent 10 suggestions to be added to the next training needs to make sure the employees are involved in the selection process. (Hiatt and Creasey 2003; Shackelford 2002; Cross and Dublin 2002) identify employees' involvement in the learning process as a main factor to succeed in the eLearning adoption. Indeed, the one who is involved in creating new thing are more likely to support it (Rosenberg, 2006). However, the final training needs and sequence of the courses are decided by Human resources according to each employee job title, unfortunately, they face a problem that some employees may have more than one title. Moreover, the interviewed users complain that they would like to participate more in the learning process and claim they do not receive these forms frequently. This indicates a bad communication between the management and users. Besides the training needs form, other ways to ensure employees' involvement is by including a feedback form in the e-Learning system to be offered to the employees after each course to take their comments, notes and suggestions.

Training manager believes that the employees, unfortunately, have a relatively low self-motivation since the completion rate was only $40 \%$, so the training has to be mandatory if they want it to succeed; she said that leaders try to persuade the employees, but they make it clear "you have to learn". They follow the "carrot and stick" approach (Sitze, 2003); they make it compulsory in many forms; first they tie e-learning achievements with job promotions as they order three online courses as a requirement for promotions, she adds we make sure to communicate the message "I cannot promise you to take a promotion without training" to employees. Also, if the employee fails in the exam, he has to pay the course cost. On the other hand, the interviewed users refuse the mandatory learning policy and make it clear that the most important motivation for them is the financial incentives. The management knows the employees point of view but unfortunately there is lack in such incentives until now, they can only get it at the end, if they finish all courses and succeed in six or more courses out of nine, they get increment on the salary. So the manager declares "if there is no financial incentives we need to search a way to enforce it".

The system in use right now is somehow having some weak points; it is mainly contains reading material which you can download and study but without any kind of interactive contents, this was upsetting for the company employees. There are discussion forums but it is not so active, the users explain that they can use it only on certain time to be defined earlier so that all the learners and the tutor are online at the same time so as to ask questions about any topic in the course and wait the response from their group tutor. Also, it is not flexible since it is developed by external company and it is not an open source system so they are not free to customize it or perform any changes they need.

Regarding the adoption measurements, she stated that they have a kind of Learning Management System (LMS) which helps in tracking the employees; the time they enter the system and when they exit, the number of downloads and number of submissions. Each employee has a profile with his/her achievements can be accessed by his/her direct supervisors who monitor their progress continuously and send them reminder messages, mentioned by the interviewed users, such as "why haven't you opened the material yet?", "do you have any questions?" or "do you understand everything?". Many evaluation techniques included in the system such as assignments with deadlines, quizzes after each part, direct supervisor feedbacks and exams at the end of the course and certificates for those succeed in the exams. They have two levels of ex- 
ams; the first one is mandatory to be completed during eight months and contains multiple choice exams, while the advanced level, which is optional until now, contains essay questions with analytical skills required. On the other hand, the department is interested in their employees' feedback about the system; at the end of each course there is an evaluation form to take their comments, suggestions and notes. Each department will have a LMS administrator who has a full control over the system. In addition they are trying to build a Course Management System which is connected to the HR department in order to choose special courses for people in especial position with specific titles according to their needs and requirements.

The new system they are developing now in the eLearning department tries to overcome all weakness points in the current system; it contains an interactive content which shows the user the learning material and steps to be taken one by one then the same steps need to be done by the learner. Also, the system is accessible anytime and anywhere, they can access it from their homes any time of the day. The system is flexible since they can update it continuously, so they make sure to include a questionnaire at the end of each course to take people feedback and comments to be taken into consideration and make any needed modifications. Besides they include a help at the main page explains how to use the e-Learning system with an online manual which assist the employee in using the system smoothly. Moreover the system has forums, emails, chatting rooms and voice or video conferences which facilitate the group work. The LMS will also automate the process of learner enrollment, registration, records, transcripts, certificates and reports and it must have to incorporate evaluation, assessment and testing capabilities.

The main problems they faced from training manager perspective was in finding resources mainly proper and rich material because of copy right issues, the need for an international well-known organization as a source to give certificates and most companies sell materials with a complete e-Learning system which is very expensive plus they already have the system and want the materials alone, even when the materials are available the current system is not interactive they can only read the material and without being changed according to employees needs since it is bought from an outside company, besides finding qualified tutors and technical expertise as the e-Learning department is a part of the IT department not the training department. Also having employees with different backgrounds and computer skills level which means different trainings are needed.

Time presents other barrier since it was hard to allocate the needed time during working hours as they have heavy work load, the users stated that they have to study at home because they do not have time to study at work, they are always under pressure to get work done on time and sometimes they have no energy to work at home so they may study only before the exam. Besides, they have communication problems between management and employees. Moreover they have some technical problems for example the current system is down frequently, and the portal can't handle some courses such as financial courses which are still on CD's until now because the current system is not ready yet. Also the material available only in English with advance language and concepts since it is the native language for company offered the system which will be hard for some employees.

Another important problem is related to the mentality issues and people cultural resistance to this new innovation. The main challenge was to change their perception and attitudes against e-Learning, since they don't believe in the web-based learning and prefer the traditional learning. This agrees with (Sullivan, 2002) theories about the need for cultural shift and with (Rosenberg, 2006) opinion "We need to talk about "e-forgetting," because to be successful at e-Learning, you have to forget the ways of your past". Other reason is tha some of them do not have the needed skills and have a fear from this new technology, besides they prefer to go outside to take training to gain days off and over time, and the main point they do not see enough incentives. Also some managers consider it as unnecessary cost and don not believe it helps the work. Finally they believe that some skills can't be educated by eLearning.

Talal Abu Ghazaleh international is planning to buy the "moodle" platform since it is an open source platform which can be downloaded, used and customized according to their needs by their e-Learning department as it is under General Public license; it contains many functionalities such as chat, forums, exams, document publishing, calendar and surveys. They will compare it with the feature of the LMS they want and find out how much customization they need then compare it with the LMS that is being developed now by their e-Learning department and find out which is better.

\section{SECONd CASE StUdy: Orange}

Orange is the biggest telecommunication company in Jordan; it plays a major role in the information and communication technology area in Jordan. It offers Internet, mobile, fixed line services, high speed internet, prepaid cards. Also it offers other services such as WAP, GPRS, MMS, SMS, chat, mobile marketing and mobile banking. Orange has almost 2.4 million customers in Jordan and 4000 employees in different sections with sites spread all over the country. Orange brand has branches in 220 different countries with 170 million customers. Jordan Telecom Group strategy is "to become the integrated operator of choice in Jordan and in the Middle East by transforming the company into a fast moving, services oriented organization, with an aim to continuously provide the highest quality of differentiated services to meet all the telecoms needs of its customers".

Four people were interviewed in this case study. They include Competency Development Director (Mr Iqab Attiyeh), Training management section Chief (Mr. Mahmoud Maragha), company instructor (Mr Khalid Harb) and one developer (Mr. Osama Salameh).

Orange training managers (Mr. Iqab Attieyeh \& $\mathrm{Mr}$ Mahmoud Maragha) started by explaining the importance of the new system in saving time and cost. It cuts the travelling time and hotels cost as their studies found that eLearning costs $30 \%$ less than traditional learning and when going outside to get training, the productivity decreases as well. Also, it helps in meeting business goals, improving human capital, gaining a competitive advantage, supporting innovation and others.

With traditional learning, instructors have to deal with different levels of students, since each learner has a unique 
set of skills, needs and knowledge. Therefore, if they focus on higher level students then lower level students with less knowledge and skills will not understand, and when focusing on low level students then higher level will get bored. E-Learning is more customized to be suitable to all levels needs. Another reason encourages them to use the e-Learning is that they do not need any new equipments since each employee already has the needed tools including PC's with high speed internet access, CD's, headsets, video cards and all other necessary devices. Also they have professional technical support so the implementation process will be easy. Nevertheless, interviewees mentioned that e-Learning still in the first stage in Jordan mainly because not all people has PC's and internet, as internet was expensive and not available in all sites outside the companies.

After that, training management chief, Mr. Maragha, explained the implementation steps of the e-Learning system in Orange. First of all, they distributed a questionnaire among the company's employees in order to measure their readiness and willingness to use the new e-Learning system. The questionnaire included some questions such as; "if you have an e-Learning system will you accept it and use it?", "do you have the needed equipments in order to use the new system?", "do you have the needed skills?"... etc. Then they analyzed the questionnaire and decided to implement the system as a result, besides defining the needed skills for employees to be trained on in order to be able to use the new system. After that, they built a business case and a feasibility study to measure the benefits, ROI and potential success. Then they defined a team for the e-learning project, unfortunately, their team did not have the needed skills because they did not have previous experience regarding this topic, so they had to get training outside, contact consultants for advice and other companies for materials and refer to them when facing any problem. Orange deals with e-Learning consultant companies like vision-pro in London, Ejabi in Jordan and UK, and other partners like cross-knowledge libraries from France. Afterwards, Orange ran a pilot project in some sections of the company to evaluate the system and send it to their consultants in Dubai, Lebanon, France and UK then take the feedback from employees and consultants and make the necessary modifications. Finally, they developed their own system inside the company to meet their business exact needs, people interests and preferences and to be able to modify the system when necessary according to their changing requirements.

The training department was responsible for the infrastructure and implementation process; Orange has an IT section within the training department other than the IT department for the whole company. The development team were consisting of 8 employees ( 2 for the material selection, 3 system developers and 3 for the flash and animation). Orange asked key skilled people to make training for employees in their sections to give them the needed instructions how to enter the site, what courses they need to download and how to use the system in general. Orange implemented two types of training: Management training as well as Technical training.

E-Learning system consists of two types of systems; learning management system with a tracking system in which defined four types of users; admin user who has the permission to make all available activities in order to manage e-Learning site, demo user who can only browse limited contents like flash movies for promotional purposes, tracked user is the current employee using the system who must follow a certain path of courses and managerial user who has the permission to see all courses and to view employees profiles . Content management system contains plain text which is simple and to the point with interactive flash movies.

Orange uses blended learning in some way as they use class rooms beside the e-Learning in some cases in which they have instructors from outside the company who have a full knowledge about the e-Learning material and make four hours session to consolidate the e-Learning courses main concepts. Some courses are targeted to certain employees in certain sectors so they use internal communication to announce the schedule of the courses two weeks before it begins and give employees five working days to complete the module after that they make a test for them and if they gain $80 \%$ or above they don't need to attend the physical lectures otherwise they have to attend the four hours session. After that they have a post assessment if they get more than $60 \%$ they pass (,) else they have to repeat the course.

Orange training system offers communication skills and computer skills to all employees in the company, nearly 4000 employees, for example they offer ICDL course and 1500 employees have to get the ICDL certificate during two weeks. They decide the training needs for each employee using their profiles and an assessment test made for them then decide according to their results.

Orange system is completely an interactive system using flash movies, one movie to each lesson, as the user takes a part in the learning process; the system asks the user to "click here", "drag and drop", "dialling to see conference"... etc. It is accessible as they can access it easily and quickly any time during and after work. In the beginning it was on LAN (Local Area Network) which they were allowed to use it only in e-Learning labs during lunch break or after work and they cannot enter it from home unless it is necessary and by pre-arrangements with the supervisor, so the average traffic flow was less than 2 from 500 employees. But after the management allow them to use it from their desks any time during the day the percentage rise to $90 \%$ and when it becomes web-based and can be accessed from home and other sites, the percentage increases). Also, it supports many languages, Arabic and English; they can download documents and follow a certain sequence of lessons.

Orange learning system is flexible too as they can customize it according to their needs. It contains help service and manuals to facilitate using the system. It offers two hours a week for open channels to submit questions and answers, as employees can upload questions to be answered by material tutors or technical support. Other collaboration methods include; emails, phone calls, forums, specific hours chatting and face to face meetings.

Orange measures the adoption of e-Learning using LMS built inside the system that can be accessed by employees' direct supervisors to monitors how many times they enter the system, how long the employees use the system, the number of hits and number of completed lessons. They found out that $92 \%$ are completing their modules. Also it contains tests, evaluation forms with pre and post-assessment in order to measure their improvement with revision to determine their retention. Besides measur- 
ing the system ROI by building a business case and analyzing the feasibility study for the project. In addition they monitor the improvement in the productivity when the employees apply what they learned in their work. Employees' satisfaction is measured as well; their feedbacks are taken about the materials, acceptability and complexity besides receive feedbacks emails with comments and suggestions in order to update the system according to them if it makes sense of course.

The interviews' results prove that leaders' support and cooperate is essential for the e-Learning adoption success; they agreed that leaders must have certain characteristics; first of all and most important they need to be convinced themselves about the system in order to persuade their team. "They can't sell it to their employees if they don't buy it first" training chief stated. They should have a good communication skills, also it is important to have the needed competence, knowledge and experience for using the system, so Orange encouraged its leaders to take a communication skills course with e-Learning subject in order to help them persuade their employees to use the system and communicate to them the benefits they can gain by using the system to their jobs, skills and overall business objectives which encourage employees in all levels and positions to use the system. "Leaders style have $70 \%$ impact on the e-Learning success" as Mr Iqab attieyeh illustrates, he adds "if he is not motivator and don't lead by example he will be a dis-motivator" As for CMP (change management plan) they apply it only on top management level.

Orange interviewees assure that motivating techniques applied in order to increase people usage of the system is the main change management factor affecting the adoption process; they study the internet hits and find out that it was huge but they prefer other sites rather than the system, hence they employ many motivation practices to guarantee high participating rate such as spreading the needed awareness about the system and the benefits they can obtain by using it.

Orange achieves this by using some marketing techniques. They use mainly emails, seminars and fun wise parties with puzzles and gifts to communicate some information; "why do we apply e-Learning?", "why do you need e-Learning?", "what benefits you can get?". Furthermore, they use internal communication to celebrate quick wins and inform all people that they have a certain achievement.

"During the first three years, e-Learning has to be mandatory and do not leave a choice to employee" Mr Mahmoud Maragha stated. He adds "after that, give them the choice" since they become more familiar with the system; experience the benefits they can gain using it, know the way to use it and how to apply what they learned in their work, but keep it connected to career path". The interviewees emphases on the need of applying this on management as well, therefore, Orange Prepared a reward structure including incentives, bonuses and gifts, the value of these rewards will be increased as the achievements increased. (Sullivan, 2002; Piskurich, 2003) define this as a major motivation for employees too.

Regarding the cultural issues, they face resistance from some employees who refuse to accept the new change, because they are used to class rooms and instructors, they do not have the needed skills, they feel uncomfortable behind the computer, or simply they have carelessness and do not want to try new things, so in order to solve this problem they offer these people 25 month salary to resign and send them home to eliminate any negative feelings. However, researchers disagree with this solution and don't believe it is the best practice. They try to change the remaining employees' mentality especially against new trends particularly e-Learning and spread the awareness about the system importance and remove any fear from new technology. They try to increase employees trust in the system by explaining the benefits they can gain by using it and let them try the system to change their negative perception. In addition they add employment conditions as any new employee to be assigned need to be fluent in English and with excellent computer skills to decrease any cultural resistance in the future.

Interviewees admitted that at the beginning they did not have strong commitments and loyalty to the system and that they faced some problems with top management as well. At first, employees are not convinced about the new system themselves since they have a traditional mentality, maybe because they belong to the old generation which increase their resistance to the new system because they don't like to try new things and they hate to admit that other young generation employees knows more than them and have more skills, they repeated "we don't need anyone to tell us what to do" as competence director stated. They claim they have no time and they have targets to be achieved. Besides they like to see employees go outside to take training; they are not conceived employees can train on their desk. So it is important to start convincing the top management and provide them with the needed skills. On the other hand many of them use the system as a way to show off and told the world we have e-Learning, so it is important to send them the message "e-Learning is not to show off" as training management chief declared.

Orange has future plan to buy new off-the-shelf system from outside company. They recommend changing the rules and instructions to be suitable to e-Learning as these present the hardest thing to be changed and need a long period.

\section{Summary of Findings: The NeW AdOPtion Model}

The two conducted cases mentioned the importance of the change management factors for a successful eLearning adoption inside the organizations. After deep and thorough investigation and analysis of the previous cases, some modifications were made on the previously suggested model. The final model is presented in Figure 2.

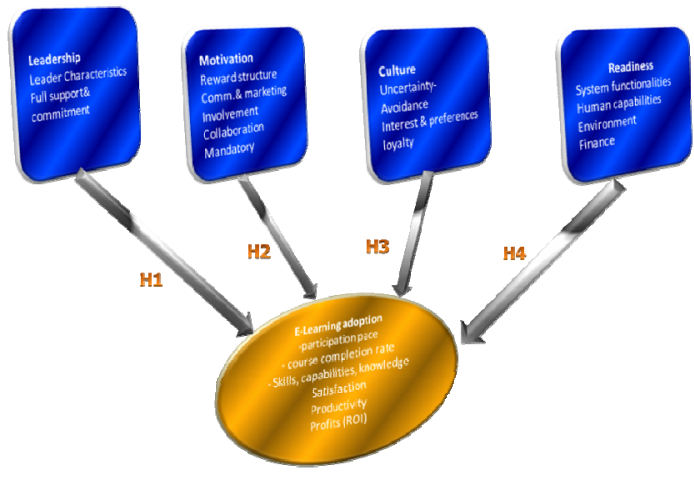

Figure 2. The Final e-Learning Adoption Model 
The interviewees agreed on the majority suggested factors affecting the adoption process including the leadership, motivation and culture. But they add another construct related to the readiness of the organization to adopt this new system. This was the main modification since it was found that Jordanian organizations still have some problems concerning the readiness issues such as the environment as the interviewees explain that a proper environment plays a key role for a successful adoption. Therefore, if the company has the needed infrastructure and the employees have the needed time, equipments and technical support the adoption has more potential to succeed. Sponsorship is another important factor in the organization readiness because the main reason for many organizations not to implement the system is that they can't afford the cost of the e-Learning system and even if they use (used) it previously they can't afford the running cost and the need for continuous updates, although they know its importance for their daily work. Currently all the organizations having an e-Learning system now are the big organization which don't have any problems regarding the training budget.

On the other hand, the interviews results eliminate some items such as the change management plan and team in the leadership construct, given that none of the successful case studies have a previously defined plan or team and however they succeed to adopt the e-Learning system. While they emphasis that the leader have to show commitment and support if they want the adoption process to succeed also they need to have certain characteristic in order to encourage people accept and use the system.

Regarding the culture it was cited by most interviewees as an essential factor affecting the e-Learning adoption since people resistance presents the main obstacle faced by the organization while adopting the new system, so all organization need to start by changing people mentality and mindsets against e-Learning to increase the adoption potential to succeed. Besides people has different interest, preferences, worries, attitudes and perspectives so different functionalities, leadership styles and motivation techniques are needed Since what work in one culture may not work in other.

Concerning the motivation both case studies emphasis on the role it plays on the adoption process and most of them, especially the users, consider it as the most important factor affecting the adoption process, including the reward structure with its incentives, bonuses, promotions, prizes and others, also the communication techniques to spread the awareness about the system and the benefits they can gain by using it, besides the employees involvement in the decisions, the need for group work and finally some managers consider mandatory learning as the best way to achieve successful adoption.

About the adoption measurement most organizations have a LMS to measure the system usage rate including the participation rate, number of hits and number of hours spent using the system, the completion rate with the gained certificates, the knowledge to be measured by exams, quizzes, assignments and other evaluation techniques. Also the employee satisfaction was measured using surveys or forms contain questions about the system to be filled by the users. Some companies measure the ROI to find out the profits they gain by using the system and the employees' productivity and how the courses help employees to increase their productivity.
The interviewees mentioned the importance of each factor for the adoption process, but it was hard to specify form their responds which one has more effect than the other as each one has different point of view and different judgment according to their own interests. So the next step will be preparing a survey for the system users in some companies which have an e-Learning system and make a quantitative analysis for this questionnaire in order to find out to what extent each factor is affecting the adoption process and make it possible to generalize this model as the sample will include a large number of users.

\section{RESEARCH CHALLENGES}

There were many difficulties faced the researchers during the research case study:

- First of all it was hard to find the cases and contact persons since the subject is new in Jordan and there is a very few number of organizations which already have e-Learning systems inside their organizations. Although the e-Learning solution companies offer a great help since they already make their study about the e-Learning market in Jordan, but the resulted list to choose from was very short.

- Setting the interviews' dates was hard too since the people in these organization, especially the managers, has a very busy schedule that is updated continuously, so to find a date and free hours to conduct these interviews was not easy. Thus the researchers try to find contacts in each company or even from outside who know the interviewees in these companies and can help set the dates with them.

- For the same company the training department and the e-learning are geographically separated they are in different buildings and different locations which make the coordination and transportation between them very hard.

- Some issues concerning trust to provide the researchers with the needed documents that contain their studies, records, statistics and others to be analyzed since they consider some of them confidential. Therefore many visits were needed to each company in order to build the needed trust.

- Receiving some conflict information from people in the same company about the same topic which was misleading some time and needs a long time and more interviews to verify the right piece of information.

- The change management term is not used in these organizations and it is new for some company employees, they use the factors and process related to it, but without knowing it is related to change management. Thus to solve this issue the researchers attempted to connect their responses and suggestions to the change management factors previously defined.

\section{VIII.CONCLUSIONS, RECOMMENDATIONS AND FUTURE WORK}

This study presents the qualitative data analysis part of the research as two different case studies were conducted in order to test a preliminary e-Learning adoption model found by reviewing the literature, the main factors were tested and some modifications were made to the preliminary model. As a result a model for e-Learning adoption 
were developed which includes four factors as the main change management factors affecting the adoption process inside Jordanian organizations. These factors include; organization readiness (System functionalities, Human capabilities, Environment, Financial readiness), leadership (commitment, characteristics), motivation (Reward structure, Communication \& marketing, employees Involvement, Collaboration, Mandatory learning) and culture (Resistance, Interests, loyalty)

In conclude the following guidelines are recommended to help achieving a successful e-Learning adoption inside organizations launching an e-learning system for the first time.

- First of all the organization must start by assessing their readiness to receive this new technological innovation.

o They have to study the e-Learning system and make sure it is customized according to their exact needs and it includes all important functionalities that motivate employees to use the system.

o They have to make sure they have the appropriate environment with the needed infrastructure, equipments and technical support.

o They must ensure that their employees have the needed skills to use the system and give them the needed training before implementing the system.

o Allocate sufficient part of the budget and resources for e-Learning needs to avoid any financial problems.

o Changing the rules and policies to be appropriate to e-Learning.

- Use the appropriate communication, marketing and awareness techniques to communicate the change vision, assure the alignment between business objectives and e-Learning objectives and spread the awareness about the system and the benefits they gain by using it to give them the desire to utilize this new system starting with the management first. And keep communication channels open all the time.

- The organization has to choose the appropriate leadership who

o Show a full support and commitment to the new system to be a good example for the team.

o Have certain characteristics such as good communication skills, influence on employees and the needed competence to use the systems and coach the team.

- The organization must motivate employees to use the system in any possible way

o Use an effective reward structure with promotions, incentives, bonuses... etc

o Use the appropriate communication channel to persuade people to accept and use the system

o Involve the employees in the implementation process and decision making, measure their satisfaction and take their feedback, comments and suggestions into consideration.

o Encourage group work and collaboration between learners and give them the opportunity to interact through discussion forums, chatting rooms, emails, conferences or even face to face meetings. o When necessary apply a mandatory learning to make sure the employee will use the system by making consequences to those not using the system.

- Make sure to prepare the appropriate culture by

o Decrease people resistance to the new technological innovation.

o Study people interest, preferences, attitudes, values and worries and make the learning process suitable to them.

o Give them the needed time to accept the new technological innovation.

o Raise their loyalty to the company by offering them comfortable environment and working climate.

- Update the system continuously according to their feedback, needs and interests, besides analyzing the faced problem and take corrective actions to ensure their commitment in the future.

- Finally Blended learning is recommended as the best way to guarantee success since it combines the benefits they can gain using the e-Learning and traditional learning besides eliminating all gaps in any of these two approaches when used alone.

Next step will be to test and validate the gained model and relations between the change management factors and e-Learning adoption using questionnaire to be sent to random sample of employees who already use the system, the sample is planned to be large in order to enhance the generalization of the results, then use quantitative methods and statistical tools in order to analyze the data and find out the correctness of the model and the strength of the relations between each factor and e-Learning adoption.

\section{REFERENCES}

[1] Al-Alawi et al., 2007, "Organizational culture and knowledge sharing: critical success factors", JOURNAL OF KNOWLEDGE MANAGEMENT, VOL. 11 NO. 22007 pp. 22-42, Q Emerald Group Publishing Limited. doi:10.1108/13673270710738898

[2] Bacal Robert, 2008, "Leadership, Communication \& Change". http://www.work911.com/articles/comchan.htm

[3] BISCHOFF Michael et al., 2003, “A Model for Systemic Change Management in Education”, International Conference on Education and Information Systems: Technologies and Applications (EISTA `03), Orlando, Florida

[4] Blanchard Emmanuel et al, 2005, "Cross-Cultural Adaptation of eLearning Contents: a Methodology"

[5] Champan Alan, 2004, "employee motivation", Situation Leadership ${ }^{\circledR}$ is a trademark owned by the Center for Leadership Studies, (C) main content Blaire Palmer. www.businessballs.com

[6] Chen Nian-Shing et al., 2004, “ASSESSMENT OF ELEARNING SATISFACTION FROM CRITICAL INCIDENTS PERSPECTIVE" , Proceedings of the 6th International Conference on Enterprise Information Systems

[7] Clarke Charles, 2003, "Towards a Unified e-Learning Strategy", Department of education and skills.

[8] Coffield Frank et al.,2004, "Should we be using learning styles? Learning and Skills Research Centre available at http://www.lsda.org.uk/files/PDF/1540.pdf

[9] Cowley Jennifer et al., 2002, "Elearning Adoption \& Marketing". Available online at http://www.elearnspace.org/Articles/ elearningadoption.htm

[10] Coultas Julie et al, 2004, "How compelling is the evidence for the effectiveness of e-Learning in the post-16 sector?", Human Centred Technology Group, School of Science and Technology, Uni- 
versity of Sussex available at http://www.reveel.sussex.ac.uk/ files/ConsultES204.pdf

[11] Creswell John, 2003, RESEARCH DESIGN, Qualitative, Quantitative, and Mixed Method approach, Sage Publications, Inc.

[12] Cross Jay and Dublin Lance, 2002, "Implementing E-Learning". ASTD

[13] de Jong P.J Jeroen and Den Hartog N. Deanne, 2007, "How leaders influence employees'

[14] innovative behavior", European Journal of Innovation Management Vol. 10 No. 1, 2007

[15] pp. 41-64 q Emerald Group Publishing Limited.

[16] Elgort Irina, 2005, "E-Learning adoption: Bridging the chasm". Available on line http://www.ascilite.org.au/conferences/ brisbane05/blogs/proceedings/20 Elgort.pdf

[17] F. Kareal* and J. Klema, 2006, " Adaptivity in e-learning", Department of Cybernetics, Faculty of Electrotechnics, Czech Technical University, Technicka 2, 16627 Prague 6, Czech Republic, CFORMATEX

[18] Gillham Bill, 2000, "Case Study Research Methods". Continuum International Publishing Group. (review on the internet).

[19] Goleman, Daniel, Richard Boyatzis and Annie McKee, 2005,

[20] Primal Leadership: Learning to Lead with Emotional Intelligence, Artech House.

[21] Haapaniemi Peter , 2002, “Smart thinking: great ideas rarely come out of thin air. Employees need ongoing training to remain focused and engaged - Innovation \& Learning”. available at http://findarticles.com/p/articles/mi_m4070/is_2002_June/ai_8743 $\underline{0219}$

[22] Hamilton Booz, 2004, "Ten Guiding Principles of Change Management", PRINTED IN USA (C2004 Booz Allen Hamilton Inc.

[23] Henderson Allan , 2003, "The E-Learning Question and Answer Book A Survival Guide for Trainers and Business Managers", American Management Association AMACOM.

[24] Hiatt M. Jeffrey and Creasey Timothy, 2003, "Change Management: The People Side of Change", Prosci Learning Center Publications, Loveland CO.

[25] Hiltz S. Roxanne and Goldman Ricki, 2005, "Learning Together Online Research on Asynchronous Learning Networks" LAWRENCE ERLBAUM ASSOCIATES, PUBLISHERS Mahwah, New Jersey London.

[26] Horton William, 2001, “Evaluating E-Learning”, ASTD

[27] Jacqueline et al, 2005, "Towards an Adaptive Cultural E-Learning System", Proceedings of the Third Latin American Web Congress (LA-WEB’05) 0-7695-2471-0/05 \$20.00 (C) 2005 IEEE

[28] Judd, Charles M., Smith, Eliot R., \& Kidder, Louise H. (1991) Research methods in social relations, (6th edition). Fort Worth, TX: Holt, Rinehart, and Winston, Inc.

[29] Kamentz Elisabeth and Mandl Thomas, 2002, "Culture and ELearning: Automatic Detection of a Users' Culture from Survey Data", 5th Annual International Workshop on Internationalization of Products and Systems (IWIPS 2002) Berlin.

[30] Kareal F. and Klema J., 2006, "Adaptivity in e-Learning", Current Developments in Technology-Assisted Education, FORMATEX 2006.

[31] Kruse Kevin, 2004, "Using the Web for Learning: Advantages and Disadvantages” by, E-Learning Guru.com, available at http://www.e-Learningguru.com/articles/art1_9.htm

[32] Mackenzie Lesley, 2004, "E-Learning and change managementthe challenge", Vantaggio Ltd, England

[33] Massy Jane, 2002, "quality and e-Learning in Europe", European elearning consultant and analyst, BIZ media.

[34] Menchaca Marylu et al. , 2003, “A Model for Systemic Change Management in Education”, International Conference on Education and Information Systems: Technologies and Applications (EISTA '03), Orlando, Florida

[35] Mungania Penina, 2003, "The Seven E-Learning Barriers Facing Employees", The MASIE Center \& e-Learning Consortium

[36] Myers, M and Avison, D., 2002, “Qualitative Research in Information Systems: A Reader. Introducing Qualitative Methods Series”, London, Sage Publications.
[37] Neuman, W, 2000, "Social Research Methods, Qualitative and Quantitative Approaches", 4th ed, Needham Heights: Allyn \& Bacon., Portugal

[38] Newman Adam,2003, "measuring success in web-based distance learning" , EDUCAUSE center for applied research, Volume 2003, Issue 4

[39] Nickols Fred 2007, change management 101, distance consultant, Available at http://home.att.net/ OPSINC/change.pdf

[40] Nininger R. James , 2001, " E-LEARNING FOR THE WORKPLACE". The Conference Board of Canada

[41] Oates, B, 2006, "Researching information systems and computing”, London, Sage publications.

[42] Orlikowski, W. and Baroudi, J., 1991, "Studying Information Technology in Organizations: Research Approaches and Assumptions", Information Systems Research 2(1), pp.1-28. doi:10.1287/isre.2.1.1

[43] Patterson et al., 2005, "Validating the organizational climate measure: links to managerial practices, productivity and innovation”, Journal of Organizational Behavior J. Organiz. Behav. 26, 379-408, Published online in Wiley InterScience (http://www.interscience.wiley.com). doi:10.1002/job.312

[44] Piskurich M. George, 2003, " The AMA Handbook of E-Learning: Effective Design, Implementation, and Technology Solutions", American Management Association AMACOM.

[45] Psycharis Sarantos, 2005, "Presumptions and actions affecting an e-learning adoption by the educational system Implementation using virtual private networks”, European journal of Open, Distance and E-learning EURODL Available on http://www.eurodl.org/ materials/contrib/2005/Sarantos_Psycharis.htm

[46] Putzhuber Werner, 2003, "From eLearning to Knowledge Management". Master's Thesis in Telematics for the Award of the Academic Degree Diplom Ingenieur at Graz University of Technology

[47] Robson Colin, 2002, "Real World Research: A Resource for Social Scientists and Practitioner-researchers ", second edition Published by Blackwell Publishing

[48] Rosenberg J. Marc, 2000, "E-Learning: Strategies for Delivering Knowledge in the Digital Age" McGraw-Hill

[49] Rosenberg J. Marc, 2006, "Beyond E-Learning", John Wiley \& Sons, Inc.

[50] Senge, P. , 2004,. Interview: The future of workplace learning and performance. T\&D Magazine, p. SS45.

[51] Peters, T. (2001, October 29). Presentation at the annual TechLearn conference, Orlando, FL.

[52] Shackelford Bill, 2002, Project Managing E-Learning, ASTD C 2002

[53] Shepherd Clive, 2003, E-Learning's Greatest Hits, Above and Beyond (C)

[54] Sims, Ronald R, 2002, "changing the way we manage change", Quorum

[55] Singh Mohini and Waddell Dianne, 2004, "E-Business Innovation and Change Management", Idea Group Publishing

[56] Sitze Amy. "What Works: Strategies for Increasing E-Learning Usage", Brandon Hall Research. Available on: http://www.brandonhallnews.com/promos/docs/WhatWorks.pdf

[57] Smith John, 2004, "motivation questionnaire", MySkillsProfile.com

[58] Straub, D., 1998, "Validating instruments in MIS research”, MIS Quarterly, Volume 13, pp.147 - 169. doi:10.2307/248922

[59] Sullivan Christine, 2002, "Getting Organization to Adapt ELearning From Challenge to Actoin.". New York Times.

[60] Van Dam Nick, 2004, The E-Learning Fieldbook: Implementation Lessons and Case Studies from Companies that are Making eLearning Work, McGraw-Hill

[61] Van Dam Nick, 2007, 25 Best Practices in Learning \& Talent Development, e-Learning for Kids Foundation (C) 2007

[62] Watkins Ryan,2005, "Learning Styles and Study Habits". Available at http://www.learningcircuits.org/2005/oct2005/watkins.htm

[63] Wang Yi-Shun, 2003, "Assessment of learner satisfaction with asynchronous electronic learning systems", Information \& Man- 
agement, Volume 41, pp 75-86, available online on sciencedirect.com doi:10.1016/S0378-7206(03)00028-4

[64] Wentling, T. et al, 2000, " e-Learning - A Review of Literature", NCSA

[65] Windmill Steven, 2005, "15 ways to drive e-Learning usage". Available at http://www.ecademy.com/node.php?id=57537

[66] Wong, K.Y., 2005, "Critical success factors for implementing knowledge management in small and medium enterprises". Industrial Management \& Data Systems, 105(3\&4).

[67] Zemaky, R. And Massy, W., 2004, "Thwarted Innovation: what happened to e-Learning and why", the learning alliance at the university of Pennsylvania) http://www.irhe.upenn.edu/ WeatherStation.html

\section{AUTHORS}

R.F. Obiedat is with University of Jordan, Amman, Jordan.

O.K. Harfoushi is with University of Jordan, Amman, Jordan.

S. S. Khasawneh is with University of Manchester, Manchester, United Kingdom.

Manuscript received March $7^{\text {th }}$ 2010. Published as resubmitted by the authors May $24^{\text {th }} 2010$. 